\title{
水泥厂余热利用前景广阔 \\ Prospect of Waste Heat Utilization in Cement Plant
}

\author{
赵亚安 \\ Yaan Zhao \\ 叶城天山水泥有限责任公司 中国·新疆 喀什 844900 \\ Yecheng Tianshan Cement Co. Ltd., Kashgar, Xinjiang, 844900, China
}

摘 要: 水泥厂的余热利用前景非常广阔。论文概述了水泥厂的余热利用优势, 并针对余热电厂生产系统、设备选型及其技 术经济性进行分析, 为相似工程提供参考。

\begin{abstract}
The prospect of waste heat utilization in cement plant is very broad. This paper summarizes the advantages of waste heat utilization in cement plant, and analyzes the production system, equipment selection and technical economy of waste heat and power plant, so as to provide reference for similar projects.
\end{abstract}

关键词: 水泥厂; 余热; 前景

Keywords : cement plant; waste heat; prospect

DOI : $10.36012 /$ peti.v2i3.2069

\section{1 引言}

水泥在建筑当中属于一种非常主要的材料, 中国的建筑 业一直在迅速的发展, 市场对水泥的质量以及数量要求等变 得非常高。为了进一步满足这一要求, 非常多的水泥厂已经 实施了扩建。按照水泥生产工艺的具体特点, 水泥窑在生产 当中会散发出高温以及中温烟气。这部分烟气携带一定的热 量(称之为废热); 如果对这部分废热实施充分的利用, 这样 可以降低能源消耗以及生产成本, 并使得环境质量得到进一 步改善。

\section{2 概述}

水泥厂散发的废热主要包含: 高温烟气废热(温度大于 $650^{\circ} \mathrm{C}$ ) 以及中温烟气废热(温度处在 $200 \sim 650^{\circ} \mathrm{C}$ 之间)。使用 方法主要包含:直接利用以及间接利用等。

水泥窑炉烟气余热的直接利用主要包含这些方面: (1)在 热交换器完成烟气余热的回收后, 通过加热空气来使得窑炉 燃料得到节约; 2)废气实施再循环返回炉子当中以节省炉子 中的燃料。
间接利用方案主要包含：(1)把烟气排入余热锅炉中, 进 而产生蒸汽, 可以直接利用蒸汽的热能满足工业以及民用供 热的需要, 也可以使用蒸汽驱动汽轮机, 向外界输出电能或 者机械能; (2)从窑炉当中排出的烟气可以直接性地送入燃气 轮机中, 把废热转化为电能或者机械能。

可以发现, 水泥厂的余热利用存在非常多的选择。应该按 照每个工厂的实际情况, 经过全面的技术以及经济比较与分 析之后, 确定要采用的方案。但总体来讲, 首先应该把高温以 及中温烟气余热转换成机械能或整合电能, 而不是直接把其 用作热能, 主要是由于功率回收和热利用相比较更加合理。

利用水泥厂的高温烟气余热进行发电是非常容易的, 余 热发电装置既可以利用燃气轮机发电机组, 也可以利用余热 锅炉+蒸汽轮机发电机组。发电机组的具体余热发电方式具 备的效率比较低, 一般使用余热锅炉+汽轮发电机的具体余 热发电方式, 如果使用全余热锅炉, 那么其发电量只和部分 生产用电相适应, 其余用电量主要需要由电网进行补充电 源, 如果中温烟气余热发电提供了所有的生产用电, 那么一 定要利用辅助燃烧式余热锅炉, 但是这样将会使得生产过程

【作者简介】赵亚安(1981 ), 男, 陕西洋县人, 二级技师, 从事水泥窑余热发电工艺运行管理研究。 
当中的油耗增加。可以发现,为了有效以及经济地利用水泥 厂当中的温烟气余热发电, 综合性地评估其不同方案是非常 必要的,这样才可以保障技术方案的合理性。中国的煤炭储 量非常丰富,但是地理分布不是非常合理。非常多的省份优 质煤炭的储量比较少, 但是劣质煤相对比较多。在一些地区, 扩建以及新建了非常多的水泥厂, 如果这些燃料(通常价格 比较低) 可以当作补燃型余热锅炉燃料, 那么就可以满足所 有电力需求, 进而在水泥生产中应用, 这样就会带来非常良 好的社会以及经济效益 ${ }^{[1]}$

\section{3 余热电厂生产系统及设备选型}

\section{1 煤炭处理系统}

余热发电站利用水泥燃料生产线的碎煤机、煤场, 储煤 以及输煤带等。在输煤带下方可以增设一条水平输送带, 这 样就可以把煤输送到主电厂的北侧位置, 然后利用倾斜输送 带把其提升到所需要的具体高度,然后利用一条短的水平输 送带落人到煤斗当中。煤斗的有效容积大致为 $170 \mathrm{~m}^{3}$, 从煤 斗当中掉出的煤会利用炉前的 3 个螺旋煤进料器把其送入 到炉膛当中。

\section{2 除灰系统}

除灰系统主要使用的是灰渣分离,全部用于水泥生产线 当中。锅炉排出的热渣使用排渣管落人到炉渣冷却器当中进 行冷却, 然后进入到炉渣破碎机当中进行破碎, 由罐车运送 到水泥生产线当中进行使用。从集尘器排出的粉尘会进入到 灰罐当中, 并送到水泥生料均化仓库当中进行使用。

\section{3 化学水处理系统}

该项目使用的水源属于地下水,按照地下水中悬浮物的 具体特点,使用混凝过滤法实施预处理,利用一级多床脱盐 法实施处理后, 利用正双层离子交换器实施 $\mathrm{H}$ 离子交换。锅 炉水在处理的过程中需要使用磷酸盐实施校正以及处理。循 环水取自地下水, 冷却塔冷却之后再次循环使用。为了防止 在系统的管壁上出现结垢,一定要加人水稳定剂。

\section{4 热力系统以及热力设备}

\section{4 .1 辅助燃烧锅炉}

当前, 中国还不存在废热利用辅助燃烧锅炉的具体定型 产品, 因此, 需要从现有的锅炉产品当中进行选择。由于该项 目使用的是中温余热对锅炉给水进行加热, 一直处于一种饱 和状态, 因此, 在锅炉设计的过程中一定要考虑节煤器以及
水冷壁的具体交换。这样可以减少热面。与此同时, 可以保持 过热器的具体热交换面积处于基本不变的状态; 在加热面上 实施上述调整之后, 炉子出口处的废气温度以及烟气温度得 到升高。为了保障锅炉的具体效率, 一定要适当对给水温度 进行降低 ${ }^{[2]}$ 。

\section{4 .2 热力系统}

热力系统使用的为一炉一机的单元系统连接, 给水系统 使用的为 2 台全容量给水原, 一台用来进行运行, 一台用来备 用; 给水原的出口主要包含 3 路, 分别送入省煤器以及 2 台余 热加热器。高压加热器需要由窑尾余热换热器实施代替。窑 尾余热器产生的饱和蒸汽一水混合物会被直接引入蒸汽鼓当 中, 然后蒸汽以及锅炉水壁产生的蒸汽会被再次合并, 进而 进入锅炉过热器当中, 过热蒸汽被引入蒸汽当中, 进而进入 待汽轮机。

\section{4 技术经济分析}

(1)充分使用水泥生产中排出的中温烟气余热, 保障排到 大气中的每一股烟气温度都不可以超过 $150^{\circ} \mathrm{C}$; 2)选择燃烧 效率比较高, 能燃烧无烟煤以及煤石的循环流化床锅炉, 以 保障其得到充分的利用; (3)降低电厂的具体能耗; (4)使得冷 凝器的真空度得到升高, 大大降低了热量消耗率; (5)减少各 种蒸汽以及热量的损失。由于利用高效的静电除尘器, 排放 到大气中的粉尘浓度就比较低, 因此, 该电厂的空气污染排 放得到了有效的控制。除此之外, 锅炉排出的所有灰渣均可 以在水泥生产当中进行利用, 进而对污染排放进行全面的控 制。从以上分析可以发现, 该项目具备非常良好的环保特性。

\section{5 结语}

总之, 利用补充燃烧式余热锅炉以及蒸汽轮发电机组发 电属于水泥厂中利用中温烟气余热的一种比较有效的途径。 关于附近燃料质量比较低下的水泥厂, 利用循环流化床锅炉 当作辅助燃烧锅炉是非常必要的, 并且其成本比较低, 可以 使得购电成本得到节省, 内部的收益率比较高。投资回收期 比较短, 具备非常良好的经济效益。

\section{参考文献}

[1] 李粀.水泥厂余热利用前景广阔——余热发电热点问题答疑[J]. 中国水泥,2017(2):16-17.

[2]王涁,水泥厂余热利用研究[J].资源节约与环保,2018(12):9. 